\title{
EDITORIAL \\ Economía criminal, el otro auge de los commodities
}

\section{Rentismo de los commodities}

Durante la primera década del siglo XXI, América Latina y otras zonas del orbe experimentaron el «auge de los commodities», en alusión a las exportaciones de materias primas y productos básicos con altas cotizaciones en el mercado mundial, especialmente minerales, petróleo, gas y productos agrícolas. Esta bonanza abrió una ventana comercial que estimuló la reorientación, incluso la regresión, de las economías latinoamericanas hacia actividades extractivistas y monocultivos a fin de aprovechar los favorables términos de intercambio. Los gobiernos de la región, emanados de fuerzas populares, orquestaron modelos como el Vivir Bien, el socialismo del siglo XXI y el nuevo desarrollismo. Todos incluían programas de redistribución de la renta a favor de los sectores excluidos por los programas neoliberales del ciclo anterior, pero el fenómeno también fue utilizado por los persistentes gobiernos neoliberales que en sentido contrario se ocuparon de transferir la renta a las arcas privadas de las corporaciones extractivas sin hacer mayores concesiones a los sectores populares. Ambas formas de gestión han estado envueltas en una gran polémica, dado que el extractivismo deviene un proyecto insustentable para incubar procesos de transformación social y se supedita a los devaneos del mercado mundial.

Si bien no son producidos por el trabajo humano, los recursos naturales — petróleo, gas, minerales, agua- son incorporados al proceso de producción, donde la máquina de hierro los devora sin consideración a su carácter no renovable o relativa escasez y los valoriza de forma superlativa merced al control monopólico. La expansión de la frontera del 
capital sobre el territorio coloca en el orden del día la cuestión de la renta de la tierra. Los más variados expedientes están abiertos: la apropiación de tierras comunales, campesinas e indígenas y su reconversión en fraccionamientos urbanos, infraestructuras, parques industriales, zonas mineras y represas; la privatización de las playas y la puesta en valor de los patrimonios culturales para el gran turismo; la demarcación de zonas exclusivas acorde a la producción industrial de bebidas alcohólicas. Las consideraciones analíticas de la renta de la tierra se hacen extensivas a otras actividades más complejas como la aplicación de la ciencia a la industria que resguarda las innovaciones y los conocimientos mediante licencias y patentes para fijar un precio mayor, una renta tecnológica; además de los complejos instrumentos financieros de corte especulativo que insuflan ganancias ficticias.

Una aplicación singular del concepto de renta reside en la economía criminal articulada por la producción, la distribución y la venta de drogas, junto con otras actividades ilícitas asociadas. La política de prohibición, la violencia de la guerra contra las drogas y la formación de mercados clandestinos propician que sean mercancías con precios artificiales muy elevados, que contemplan una renta criminal, una peculiar forma de ganancia extraordinaria, a tal grado que la exportación de drogas ilícitas representa un sector muy lucrativo y configura el «otro auge de los commodities». La alta rentabilidad de esta economía encubierta opera en buena medida por la escasez relativa de tierras disponibles para cultivo, cosecha, procesamiento y almacenamiento de drogas como mariguana y amapola, debido a la política prohibicionista que criminaliza a los productores y convierte dicha actividad en clandestina. Derivado de ello, la droga, en tanto mercancía, se presenta como un producto aparentemente escaso por su carácter ilegal; en tanto, la persecución policiaco-militar empuja la cadena de valor (producción-distribución-consumo) hacia los ámbitos del mercado negro, donde se forma un precio de monopolio que 
arroja fabulosos ingresos —el pujante «dinero sucio»- que a la postre tienen que ser «blanqueados» para reinsertarlos a los circuitos financieros y empresariales formales y legales. Los bajos fondos de dicho mercado son operados por organizaciones armadas ilegales que cometen distintos tipos de delitos, a sabiendas de que cuentan con la intervención subrepticia del Estado como instancia creadora, administradora y reguladora de un negocio muy lucrativo en el que participan fuerzas militares y policiales que criminalizan o tutelan a productores, traficantes y consumidores. En adición, el sector financiero canaliza el dinero negro hacia diversos instrumentos financieros, paraísos fiscales y proyectos de inversión. Un poderoso sector empresarial reinvierte tales dineros en proyectos de negocio e importantes parcelas del sector político reciben sobornos. Al final de cuentas, la burbujeante economía criminal no es más que un eslabón dinámico y oscuro de la economía capitalista (Márquez, 2015).

\section{Necroeconomía}

Dentro del tráfago comercial encabezado por la exportación de automóviles maquilados y migrantes (Márquez, 2007), en la economía mexicana han tomado un gran relieve las ventas al exterior de drogas y el consecuente lavado de dinero en los circuitos financieros y empresariales. El empuje narcótico-mercantil está inmerso en redes globales de capital cuya pulsión es la fórmula del dinero negro progresivo: hacer más dinero mediante la violencia, el monopolio clandestino y la corrupción, sin importar las consecuencias. Un entramado de actividades ilícitas contribuye a la bonanza de una economía que articula ganancia y muerte: drogadicción, tráfico de drogas, trata de personas, secuestro, extorsión, entre otras. Las organizaciones criminales diversifican las fuentes de ingresos al incluir desde la venta de commodities ilícitos, como las drogas (mariguana, opio, cocaína y metanfetaminas), y lícitos, como minerales 
y petróleo, hasta formas de despojo (robo de tierras y bienes comunales), extorsión (cobro ilegal de impuestos y venta de protección) y corrupción (cooptación de funcionarios públicos), entre otras. No obstante, el tráfico de drogas es la actividad más redituable: entre 60 mil y 70 mil millones de dólares se movilizan en torno a los estupefacientes, un monto que duplica, por ejemplo, las remesas enviadas por los migrantes.

Pese a la declarada "guerra contra el narcotráfico», México figura como una potencia exportadora de drogas, sobre todo hacia Estados Unidos, el gran mercado de consumo con 22.5 millones de habitantes que padecen distintos niveles de adicción (NIDA, 2013). Asimismo, es el segundo productor mundial de opio y heroína, después de Afganistán, país con el que comparte la segunda posición como productor de mariguana, encabezada por Marruecos (UNODC, 2013). La capacidad de producción es amplia. En el país se cultivan alrededor de 12 mil ha de la adormidera, precursora del opio y la heroína, en tanto que el potencial productivo de heroína supera 30 veces a Colombia, país considerado por Estados Unidos como su principal fuente de abasto (UNODC, 2013). La tendencia es que México incremente más la producción de opiáceos derivados de la adormidera, la mariguana y las drogas sintéticas (Reveles, 2015). El auge exportador se sustenta en una plataforma comercial que cuenta con infraestructura de almacenamiento y distribución de cocaína procedente de Sudamérica, aunado a la producción y exportación de heroína, mariguana y drogas sintéticas al vecino del norte y otros más instalados en el Norte global. El papel asignado a México en este contexto es el de proveedor de drogas de acuerdo con la demanda de sustancias ilícitas, en un mercado controlado por el principal consumidor, Estados Unidos. La relación narcótica entre ambas naciones profundiza el añejo intercambio desigual: México provee drogas a costa de desencadenar una violencia irracional, la violación masiva de derechos humanos y la fractura del tejido social; y Estados Unidos lava el dinero y se apropia del 
mayor margen de la renta criminal, exporta armamentos y consume las drogas.

Por las venas de la economía mexicana circula un flujo de dinero que representa 150 mil millones de dólares, por lo que se ubica en el tercer lugar mundial con mayor torrente de dinero ilícito, sólo debajo de China y Rusia; en el marco del Tratado de Libre Comercio de América del Norte (TLCAN) el dinero criminal se ha incrementado para alcanzar una media anual de 6.3 por ciento respecto del producto interno bruto (PIB) (CESOP, 2017). El lavado de dinero mueve miles de millones de dólares en el mundo y la mayor parte del dinero procedente de actividades ilícitas en México, como venta de drogas, trata de personas y delitos cibernéticos, se envía por varios canales financieros y se deposita en paraísos fiscales; luego se traslada a otros países y después se compran bienes inmuebles que se venden para comprar activos. En su progresión, el dinero sigue varias transacciones operadas por sucesivas empresas de fachada que filtran y limpian la «suciedad» que lo impregna. El destino final del dinero lavado son los países del Norte global en los que existen sistemas que resguardan la propiedad privada y no indagan la procedencia de las fortunas. En esos países la narcoburguesía lo invierte con el objetivo de generar beneficios o en propiedades que le permiten llevar un tren de vida de primer mundo. Se estima que 70 por ciento del dinero «sucio» derivado de actividades criminales se transfiere a Europa, Estados Unidos y Canadá, donde se presume la existencia de Estados de derecho avanzados que garantizan mecanismos institucionales para integrar los capitales mal habidos y brindan la seguridad jurídica condescendiente con el estatuto de la propiedad privada para lavarlo y convertirlo en dinero legal, invertirlo en busca de beneficios o adquirir propiedades y disfrutar del estilo de vida de las grandes urbes. El restante 30 por ciento se tipifica como gasto operativo de las organizaciones criminales, por lo cual se canaliza a la compra de políticos y autoridades, el financiamiento 
de campañas electorales y la adquisición de edificios e infraestructura (Buscaglia, 2015). El efecto multiplicador del dinero criminal se asocia a la necesidad de «blanquearlo» a través de su inserción en circuitos financieros formales (en específico bancos comerciales y casas de cambio), pasando por la venta de bienes suntuarios (joyería, automóviles de lujo, obras de arte) hasta un amplio abanico de proyectos de inversión en la industria turística, el sector inmobiliario, la agroindustria, entre otros.

La economía criminal dispone de una gran capacidad para ofrecer empleo, a cerca de 500 mil personas, que se distribuyen en las más diversas ocupaciones: siembra de drogas (300 mil), narcomenudeo, transporte, distribución e informantes (160 mil) y cargos de liderazgo (40 mil), según lo reconoce la Secretaría de la Defensa Nacional (Merlos, 2008). Esta cantidad de personas supera tres veces al personal de Petróleos Mexicanos (Pemex), la principal empresa pública, ahora cada vez más desmantelada por la «reforma energética» neoliberal.

\section{Violencias estatal y protoestatal}

El Estado es la cristalización del proyecto histórico de la clase dominante que bajo el periodo neoliberal se ha ejercido como dominación pero sin consenso (Calveiro, 2012). Incluso se ha propalado la creencia de que es una instancia que sobre todo resguarda el orden y la seguridad merced a disponer «del monopolio de la violencia legítima» y de contar con la potestad de ser fuente de la legalidad, la ideología y la verdad, independientemente de las necesidades sociales, por lo que fetichiza el poder. En los hechos es una estructura concentrada de modo oligárquico, subordinada a los poderes externos de los grandes capitales y a los intereses geoestratégicos de las potencias capitalistas encabezadas por Estados Unidos, de tal forma que la población se ha ido desgarrando. La crisis de legitimidad del Estado ha estallado en la comunidad imaginaria y la preponderancia 
de poderes fácticos en todos los planos espaciales ha fragmentado la presunta unidad territorial.

En esa lid el gobierno mexicano ha declarado una «guerra contra el narcotráfico» desprendida de la Iniciativa Mérida, el esquema de seguridad diseñado por Estados Unidos, cuyo antecedente es el Plan Colombia y la propia «guerra contra las drogas» de Estados Unidos (Astorga, 2015). No obstante, la noción de guerra es un atributo de los Estados nacionales que en el siglo pasado significaba la confrontación armada y sin concesiones hasta desembocar en la rendición total e incondicional del enemigo. Sin embargo, la guerra entre el Estado nacional y los cuasi-Estados dentro de un país como México registra una y otra vez episodios bárbaros y se despliega no precisamente como una guerra civil sino como una suerte de cruzada ideológica; aunque sus objetivos selectivos tienen el doble cometido de resguardar el modelo neoliberal depredador y su régimen político autoritario. Se combate en algunos frentes, pero la economía criminal no se destruye, pues el capital criminal es una fracción activa del capital colectivo y existen múltiples intereses en el ámbito nacional que sustraen enormes beneficios de la necroeconomía.

Resulta sintomático que en el ámbito de los Estados nacionales periféricos los considerados cuasi-Estados, en tanto formaciones socioterritoriales articuladas por capitales criminales, disponen de un poder fratricida dentro de espacios provistos de una soberanía acotada, como sucede con el Estado nacional ampliado, sometido a su vez por los poderes de los Estados centrales y los poderes económicos de los capitales monopólicos. La estructura de poder reconoce jerarquías y espacios soberanos, desde las potencias económicas y militares que dominan el sistema mundial, en particular Estados Unidos, pasando por los Estados nacionales y su entramado de instituciones, legislaciones y fuerzas armadas, las corporaciones capitalistas que organizan el territorio en mercados, fuentes de trabajo barato y abastos de materias primas, hasta regiones específicas tomadas por 
asalto por organizaciones criminales para el cultivo, procesamiento, almacenamiento y distribución de drogas, además de la comisión de otros hechos ilícitos. No puede perderse de vista que hay otros espacios virtuales, cibernéticos, políticos y administrativos donde circulan los grandes flujos de dinero criminal que articulan al conjunto de poderes económicos, políticos y militares en una amalgama de operaciones legales e ilegales que configuran espacios de alta rentabilidad. Las fuerzas armadas (ejército, marina, policía federal y policías estatales y municipales) pueden acotar el dominio de las organizaciones criminales; no obstante, existen elementos que hacen suponer la colusión entre instancias estatales y criminales, a tal grado que la violencia se confunde como el control territorial de ambas estructuras, estatales y protoestatales. La confrontación entre el Estado y los cuasi-Estados puede ser extremadamente violenta, intermitente o puramente declarativa, si bien entre ellos existe una zona gris donde guarece la sociedad civil inerme que padece lo peor de los delitos y al mismo tiempo el acoso de las fuerzas armadas estatales. El Estado ha liquidado o apresado a determinados jefes de algunas organizaciones $y$ en apariencia ha protegido a otros, pero en cualquier caso no ha logrado o no ha querido desarticular a los proto-Estados en ninguna región del país y mucho menos a la economía criminal y su fuente de ganancia extraordinaria.

\section{Nueva geografia del proto-Estado}

Las estructuras formales del Estado provistas de autoridad, sociedad, economía y cultura establecen relaciones con formas paralelas de cuasi-Estados criminales que disponen de sus estructuras de autoridad, economía, cultura y organización social con fuerte arraigo en la sociedad civil de regiones de Sinaloa, Durango, Coahuila, Tamaulipas, Michoacán, Guerrero, Estado de México y otras entidades del país. 
Pese a que dentro del Estado no existe otra instancia paralela reconocida con las características de organización interna, autogobierno, monopolio de la violencia legítima y soberanía (los estados de la república que se denominan «libres y soberanos» están subordinados al Estado nacional), en varias regiones operan organizaciones criminales como la Federación de Sinaloa, los Zetas de Tamaulipas, los Caballeros Templarios en Michoacán, Guerreros Unidos en Guerrero y Jalisco Nueva Generación en Jalisco. Constituyen una especie de proto-Estados que disponen de estructuras diferenciadas y jerárquicas, detentan un dominio territorial, ejercen un poder ilegal y brutal mediante el uso de la fuerza, cobran «impuestos» a la sociedad, asignan recursos de manera inapelable, ejercen una pseudojusticia que resuelve de modo expedito disputas entre particulares y mantienen una red compleja de relaciones con su entorno externo. Sin embargo, no son instancias separadas del Estado nacional, sino que tienen fuertes vínculos con las estructuras formales y legales: financian campañas electorales y partidos políticos, cuentan con nóminas paralelas de policías y militares de distintos rangos. Las organizaciones criminales, en ámbitos territoriales específicos, sobre todo locales, pueden ejercer presión y llegar a amedrentar a determinadas autoridades y burocracias, incluso se presume que pudieran «capturar» a instancias estatales y reconvertir a cuerpos policiacos y militares en brazos armados de la criminalidad. Empero, el Estado nacional no ha sido debilitado al punto de ser capturado por la criminalidad, más bien junto con las estructuras del poder ha configurado una boyante economía criminal que se beneficia de la política prohibicionista y punitiva diseñada por las propias instituciones estatales para soportar la pujanza de la renta criminal.

En definitiva, la renta criminal sustenta la figura de proto-Estado y el auge de la economía criminal. Esta forma paralela y contrahecha del Estado criminal reparte la renta entre segmentos preclaros del Estado nacional (Meyer, 2016). La bonanza de la economía criminal dimana del 
mundo de la corrupción y la cooptación de las agencias del Estado que se requieren para la formación y administración de los mercados. Una pléyade de funciones y actividades se subsumen al esquema operativo de la necroeconomía: ejército, marina, policías, jueces, notarios, diputados, senadores, presidentes municipales, etcétera (Garay y Salcedo, 2012). En la nueva geografía de la economía criminal varias entidades han sido catalogadas como narcoestados y los narcotraficantes son prósperos empresarios que acumulan riquezas y realizan actividades exportadoras de drogas y materias primas (commodities) hacia los grandes centros industriales. Por ejemplo, los Caballeros Templarios exportaban hierro a China desde el puerto de Lázaro Cárdenas, Michoacán, y los Zetas exportaron carbón de Coahuila. Por esta vía, hay una imbricación entre el extractivismo de materias primas y la economía criminal.

\section{Resistencias y potencias}

Las clases populares mexicanas se encuentran supeditadas a los poderes legales e ilegales, que por igual se fundan en la violencia y expanden sus ámbitos de dominio mediante el despojo y la explotación, amén de que instrumentan formas de dominio basadas en el miedo y el terror, enmarcados en la necropolítica (Mbembe, 2011). De por sí la forma estatal legal bajo la democracia burguesa y la acumulación monopolista subsume a la ciudadanía, ahora con la proliferación de la forma proto-Estado y la economía criminal, la figura de ciudadanía se difumina al instante. La conjunción de la violencia legal e ilegal convierte a la población en una ciudadanía precaria, un conjunto amorfo de súbditos sometidos por una minoría de tiranos. No obstante, diversos movimientos sociales de víctimas han impugnado la política de violencia militarizada y la criminalización encubierta en la «guerra contra las drogas», como el Movimiento por la Paz con Justicia y Dignidad, las organizaciones 
que defienden a los migrantes centroamericanos y los movimientos que exigen la presentación con vida de los 43 estudiantes desaparecidos en Ayotzinapa. Tales organizaciones y movimientos se inscriben en la tónica de la resiliencia, a la vez que se articulan con otros movimientos que intentan reconstruir la ciudadanía en un sentido amplio y propiciar la formación de sujetos políticos alentados por otra cultura política, en un preclaro intento de cambiar el país, no a través del régimen político corrompido o la alternancia electoral de las elites, sino al forjar una nueva subjetividad, una nueva ciudadanía, un poder destituyente que eventualmente abra paso a otro proyecto civilizatorio (Agamben, 2014).

\section{Referencias}

Agamben, G. (2014). «Para una teoría de la potencia destituyente», Fractal (74). Astorga, L. (2015). «QQué querian que hiciera?» Inseguridad y delincuencia organizada en el gobierno de Felipe Calderón. México: Grijalbo.

Buscaglia, E. (2015). Lavado de dinero y corrupción politica. El arte de la delincuencia organizada internacional. México: Debate.

Calveiro, P. (2012). Violencias de Estado. De la guerra antiterrorista y la guerra contra el crimen como medios de control global. México: Siglo XXI.

Centro de Estudios Sociales y de Opinión Pública (CESOP) (2017). Estructuras financieras del crimen organizado. México: Cámara de Diputados.

Garay, L. y Salcedo, E. (coord.) (2012). Narcotráfico, corrupción y Estados. Cómo las redes ilicitas han reconfigurado las instituciones en Colombia, Guatemala y México. México: Debate.

Márquez, H. (2007). «Migración y desarrollo en México: entre la exportación de fuerza de trabajo y la dependencia de las remesas». Región y sociedad 19(39).

Márquez, H. (2015). «La razón criminal del narcocapitalismo», Observatorio del desarrollo 4(14). 
Mbembe, A. (2011). Necropolítica. Santa Cruz de Tenerife: Melusina.

Merlos, A. (2008). «Hay 500 mil narcos», El Universal, http://archivo.el universal.com. $\mathrm{mx} /$ notas/528874.html

Meyer, L. (2016). Distopia mexicana: perspectivas para una nueva transición. México: Debate.

National Institute of Drug Abuse (NIDA) (2013). «Drugs Facts», https:// d14rmgtrwzf5a.cloudfront.net/sites/default/files/drugfacts_nationwide trends_sp_06-25-13_final_0.pdf

Reveles, J. (2015). Échale la culpa a la heroina. De Iguala a Chicago. México: Grijalbo.

UNODC (2013). World Drug Report 2013. New York: United Nations. 